\title{
A 10 Year Post Mortem Study of Choking Cases Brought to the Mortuary of a Tertiary Care Hospital in Imphal
}

\author{
Memchoubi Phanjoubam ${ }^{1}$, Supriya Keisham ${ }^{2}$, Th. Meera Devi ${ }^{3}$, Seram Elizabeth Devi ${ }^{4}$, Soibam Neha ${ }^{4}$ \\ ${ }^{1}$ Associate Professor, ${ }^{2}$ Assistant Professor, ${ }^{3}$ Professor and Head, ${ }^{4}$ Post Graduate Trainee, Department of Forensic \\ Medicine and Toxicology, Regional Institute of Medical Sciences, Imphal
}

\begin{abstract}
Choking is the obstruction of air flow into the lungs and is almost always accidental. In this paper, cases of choking mistaken to be deaths due to foul play are studied. Any complaint is not true unless it is proved so. In all these cases, family members blamed the deaths on some parties who were in fact completely innocent. Meticulous autopsy helped in establishing the exact cause of death in these cases by disproving the false charge of assault. From the legal standpoint, the importance of establishing an exact diagnosis is obvious.
\end{abstract}

Keywords: Allegations, foul play, choking.

\section{Introduction}

Choking is the mechanical obstruction of the flow of air from the environment into the lungs. Choking prevents breathing and can be partial or complete, with partial choking allowing some, although inadequate flow of air into the lungs. Prolonged or complete choking results in asphyxia which leads to anoxia and is potentially fatal. Choking can be caused by (i) physical obstruction of the airway by a foreign body, (ii) respiratory diseases that involve obstruction of the airway and (iii) compression of the laryngopharynx, larynx, or trachea in strangulation and intravenous larygospasm. ${ }^{1}$ Obstruction of the airway can occur at the level of the pharynx or trachea. Food that can adapt their shape to that of the pharynx (such as bananas and gelatinous candies) can be a danger not just for children but for persons of any age. ${ }^{2}$ Among some of the most notable cases of choking deaths, mention may be made of Air Marshal Subroto Mukherjee, the first Chief of the Air Staff of the Indian Air Force who died

\section{Corresponding Author:}

Memchoubi Phanjoubam

Associate Professor, Department of Forensic Medicine and Toxicology, Regional Institute of Medical Sciences, Imphal

e-mail: mem010177@gmail.com on November 8, 1960 at Tokyo, by choking on a piece of food lodged in his windpipe. ${ }^{3}$

On the other hand, allegations of excessive use of force and extrajudicial killings by police or armed forces are common in the north-eastern state of Manipur. A petition filed by two non Governmental organizations with the Supreme Court of India claimed that at least 1528 extrajudicial killings were carried out by the police or security forces in Manipur during 1979-2012 (supreme Court of India Writ Petition [Criminal] No. 129 of $2012 .{ }^{4}$ Interestingly, one of the present cases was also brought as a case of death due to police atrocity which was disproved by autopsy as it turned out to be due to choking and a case of natural death.

\section{Material and Method}

A retrospective analysis of all the deaths due to choking was done in the Department of Forensic Medicine and Toxicology of a tertiary care teaching hospital in Imphal. After obtaining Institutional Ethics Committee clearance, the cases were studied with regard to the sex and age wise distribution, type of food present, site of obstruction, association with alcohol and activity before choking.

\section{Results and Observations}

A total of eight cases were brought for autopsy in the 10 -year period. All the cases were males and all 
these cases were associated with allegations of foul play. Maximum incidence was seen in the 21-30 yr age group followed by $0-10$ and 11-20 yr age groups as shown in Fig. 1. Presence of food particles in the respiratory tract beyond the trachea was seen in seven cases and alcohol was associated in six cases as shown in Figs. $2 \& 3$. Table 1 shows the activity before death. In one case, a three-year old boy was fed a piece of bread and he choked on it and died the next day due to aspiration bronchopneumonia. In four cases, the victims were found dead and on autopsy food particles were seen in the respiratory tract beyond the bronchi. In one case, the victim played football just after food and started choking and died. In another case, the victim slept just after dinner and got up choking and died. There was also a case where the victim took a walk after dinner and started choking and died. Regarding the site of obstruction, food particles reached the bronchioles in 1 case, trachea in one case and bronchi in five cases and in the case of the child no food particles could be seen as the child had consumed only a small piece of bread (Table 2).Regarding stomach contents, five cases had semi-digested food particles, one case had rice particles, another case had vegetable particles and in the case of the three-yr old child, only some mucoid substance was present (Table 3). Similar substances were present in the respiratory tracts of the victims.

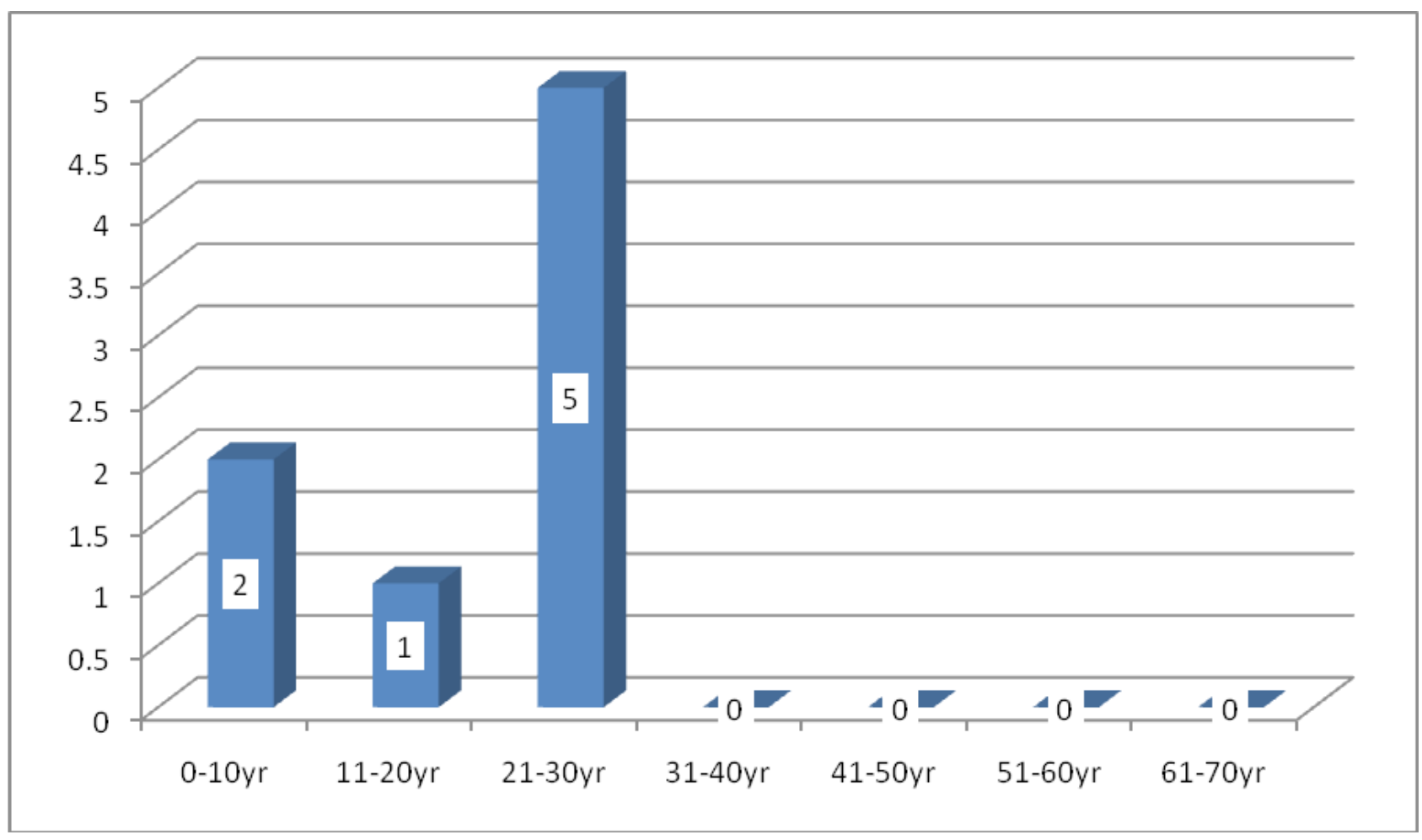

Fig. 1: Age wise distribution 


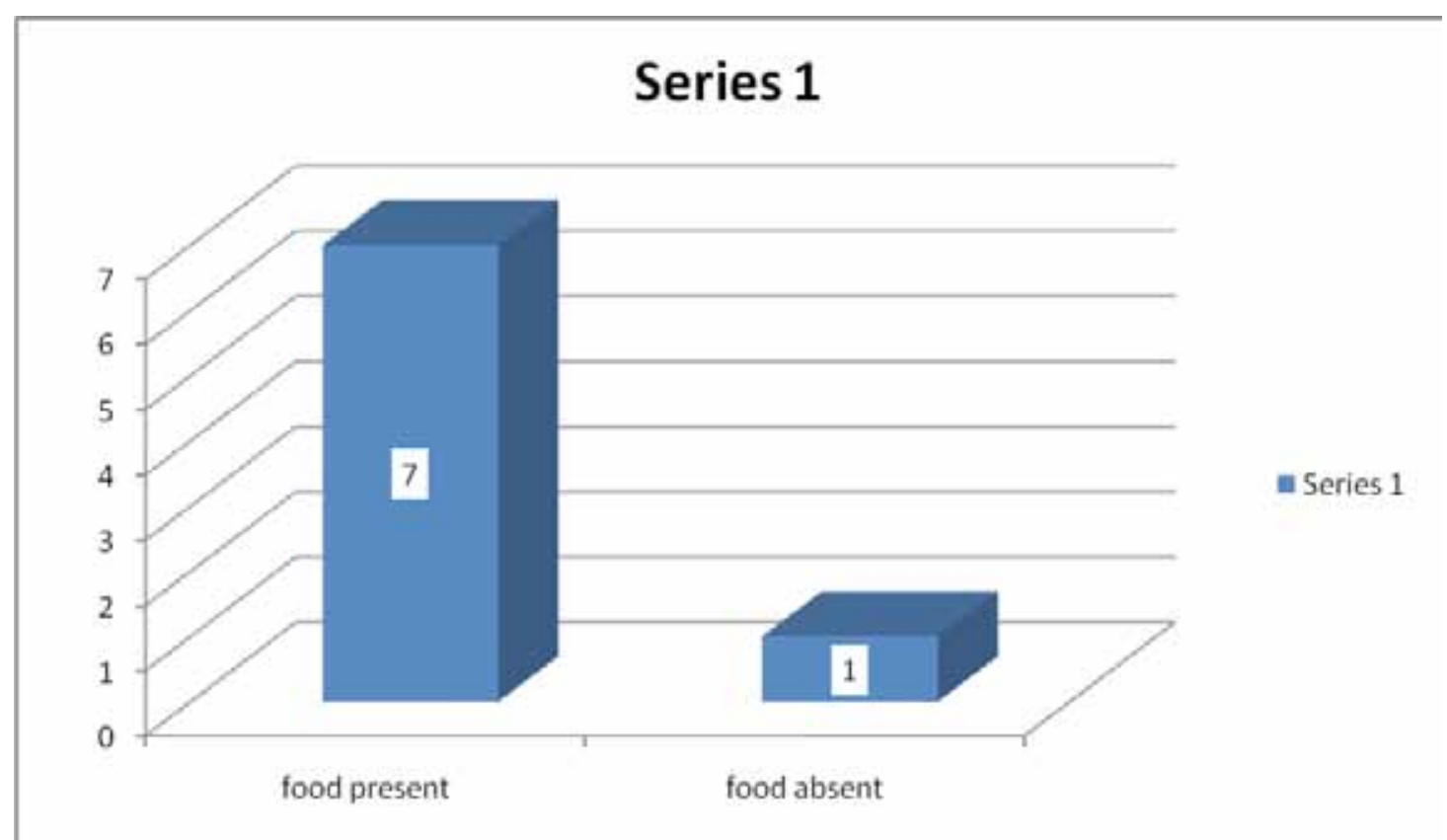

Fig. 2: Presence of food particles in the respiratory tract

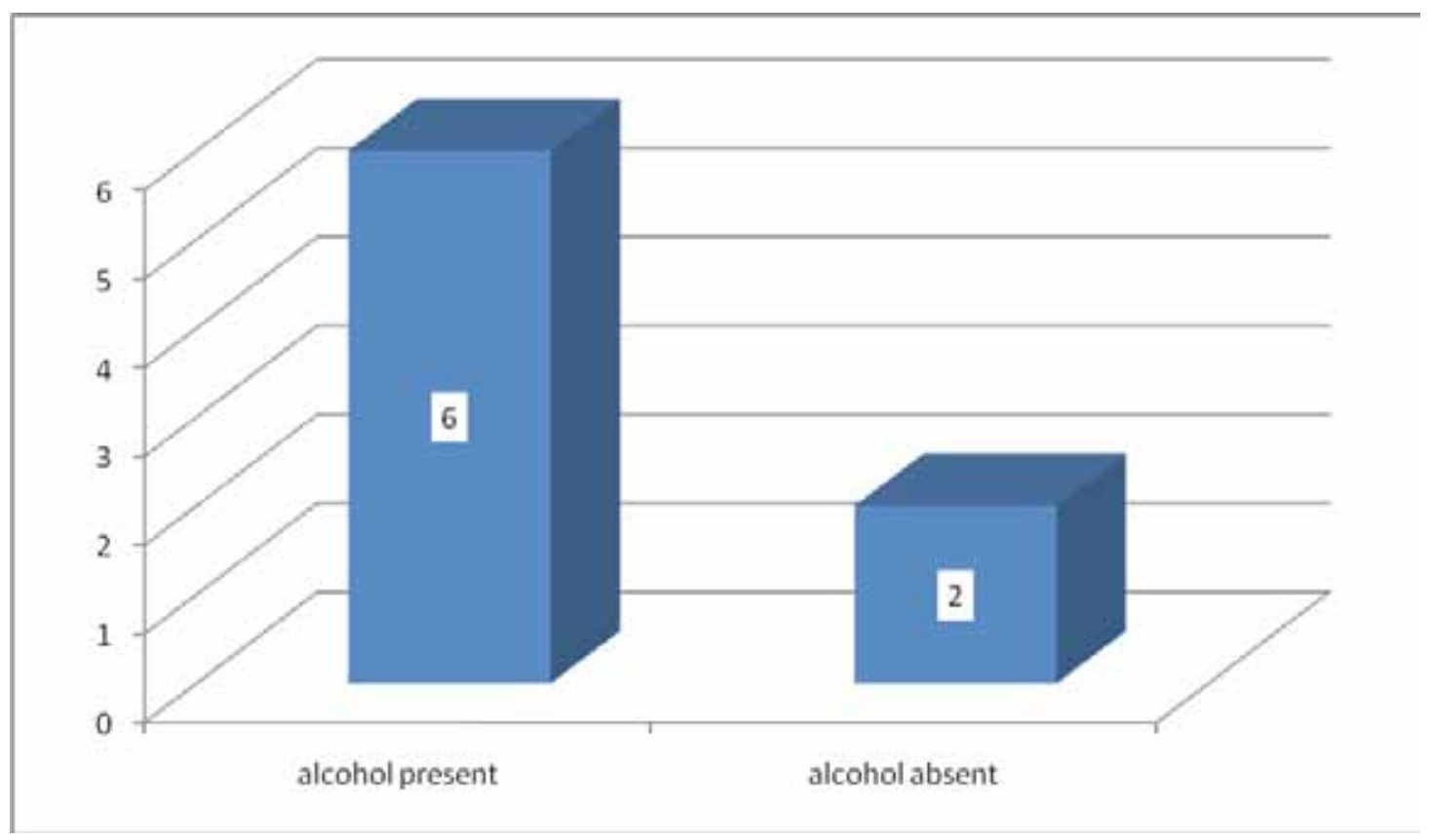

Fig. 3: Presence of alcohol

Table 1: Activity before death

\begin{tabular}{|l|c|}
\hline Activity & No. of cases \\
\hline Eating & 1 \\
\hline Sleeping just after dinner & 1 \\
\hline Walking after dinner & 1 \\
\hline Playing football after lunch & 1 \\
\hline Found dead & 4 \\
\hline
\end{tabular}

Table 2: Obstruction site

\begin{tabular}{|l|c|}
\hline Site of obstruction & No. of cases \\
\hline Larynx & 0 \\
\hline Trachea & 1 \\
\hline Bronchi & 5 \\
\hline Bronchioles & 1 \\
\hline
\end{tabular}


Table 3: Stomach contents

\begin{tabular}{|l|c|}
\hline Stomach content & No. of cases \\
\hline Rice & 1 \\
\hline Vegetables & 1 \\
\hline Semi-digested food & 5 \\
\hline Mucoid substance & 1 \\
\hline
\end{tabular}

\section{Discussion}

Airway obstruction can be of anatomical or mechanical origin. Anatomical obstruction may be produced by anatomical structures such as tongue, swollen tissues of mouth and throat like inflamed epiglottis. In these natural deaths, there is obstruction of the airway by the inflamed epiglottis and adjacent soft tissue and are of anatomical origin as said above.

Mechanical obstruction occurs due to foreign body. ${ }^{5}$ Physical findings of wheeze, rhonchi, stridor, or retractions were associated significantly with a diagnosis of an unwitnessed foreign body. ${ }^{6}$ Death due to choking is due to unintentional ingestion or inhalation of food or other objects resulting in the obstruction of respiration. ${ }^{7}$

Choking is almost always accidental. In the above cases, the deaths which were suspected to be due to foul play, turned out to be accidental deaths due to mechanical airway obstruction by food particles. Some of the common risk factors of choking are old age, poor dentition and alcohol consumption. Other risk factors include chronic disease, sedation, eating risky food and senility. ${ }^{7,8,9}$ although choking is reported to be higher in the age above 65 yrs, we saw no case in this age group. ${ }^{9}$ In the present cases, there was history of consumption of alcohol in one case. Some of the other common causes of choking include swallowing large pieces of poorly chewed food, eating while talking excitedly or laughing, or eating too fast and walking, playing, or running with food or object in the mouth. ${ }^{5}$ In one case the person was playing football just after eating. In another case, the person went for a walk after dinner and died due to choking.

On the other hand, gastric contents are aspirated in the windpipe due to the handling of the body, or as a terminal event in natural death (agonal artefact) or due to resuscitation. Hence, agonal artefact may look like a case of choking and vice versa. However, the difference lies in the extent up to which food particles enter the lungs. In choking, the bronchioles are filled with food particles whereas in agonal artefact, food particles may reach only up to the larynx. ${ }^{10}$ In all these cases the food particles were found beyond the bronchi which ruled out agonal artefact.

Even though the allegation was that of foul play, the points in favor of choking in these cases were the absence of signs of external or internal physical injury (except minor abrasions in two of the cases), the presence of food particles in the respiratory tract reaching up to the bronchioles (which ruled out agonal artefact) and the presence of signs of asphyxia.

\section{Conclusion}

Any complaint is not true unless it is proved so. Meticulous autopsy helped in establishing the exact cause of death in these cases by disproving the false charge of assault thereby avoiding public outrage. From the legal standpoint, the importance of establishing an exact diagnosis is obvious. Whenever death is attributed to heart disease, the beneficiary of the estate is denied the double indemnity insurance benefits that are allotted when death can be proved to have occurred as the result of accidental inhalation of food. Therefore, establishing choking as the real cause of death gives two benefits, i.e., allegations are allayed and indemnity benefits are doubled if the life of the deceased has been insured.

\section{Conflict of Interest: Nil}

\section{Acknowledgement: Nil}

\section{Source of Funding: Nil}

Ethical Clearance: Taken from Research Ethics Board,Regional Institute of Medical Sciences, Imphal.

\section{References}

1. Choking. Available from: https://www.revolvy. com/main/index. php?s=Choking \& item type=topic. [Last accessed on 2017 Jan 20].

2. Sayadi R. Swallow Safely: How Swallowing Problems Threaten the Elderly and Others. 1st ed. Natick, MA: Inside/Outside Press; 2010. p. 46-7.

3. The Saga of a Soaring Legend. IAF. Available from: $\mathrm{http}: / / \mathrm{www}$. indianairforce.nic.in. [Last accessed on 2017 Jan 18].

4. Available from: http://www.supremecourtofindia. nic.in/FileServer/2016-07-08_1467967629.pdf. [Last accessed on 2017 Jan 18]. 
5. Pawar MN, Patil DT, Goodbole HV. Uncommon Choking: A case report. Medico-legal Update 2008;8:3-4.

6. Louie JP, Alpern ER, Windreich RM. Witnessed and unwitnessed esophageal foreign bodies in children. Pediatr Emerg Care 2005;21:582-5.

7. Berzlanovich AM, Fazeny-Dörner B, Waldhoer T, Fasching P, Keil W. Foreign body asphyxia: A preventable cause of death in the elderly. Am J Prev Med 2005;28:65-9.
8. Dolkas L, Stanley C, Smith AM, Vilke GM. Deaths associated with choking in San Diego county. J Forensic Sci 2007;52:176-9.

9. Kramarow E, Warner M, Chen LH. Foodrelated choking deaths among the elderly. Inj Prev 2014;20:200-203. doi:10.1136/ injuryprev-2013-040795

10. Subrahmanyam BV. Modi's Medical Jurisprudence and Toxicology. 22nd ed. New Delhi: Butterworths; 1999. 